Article

\title{
Association between FADS Gene Expression and Polyunsaturated Fatty Acids in Breast Milk
}

\author{
Huimin Tian ${ }^{1}$, Haitao $\mathrm{Yu}^{2}$, Yiqi Lin ${ }^{3}$, Yueting $\mathrm{Li}^{2}$, Wenhui $\mathrm{Xu}^{2}$, Yiru Chen ${ }^{2}$, Guoliang Liu ${ }^{2}$ and Lin $\mathrm{Xie}^{2, *}$ \\ 1 Department of Pediatric Nursing, School of Nursing, Jilin University, Changchun 130021, China; \\ tianhm@jlu.edu.cn \\ 2 Department of Nutrition and Food Hygiene, School of Public Health, Jilin University, \\ Changchun 130021, China; htyu19@mails.jlu.edu.cn (H.Y.); ytli20@mails.jlu.edu.cn (Y.L.); \\ xuwh20@mails.jlu.edu.cn (W.X.); yrchen20@mails.jlu.edu.cn (Y.C.); glliu@jlu.edu.cn (G.L.) \\ 3 Jilin Women and Children Health Hospital, Changchun 130061, China; linyiqi791222@126.com \\ * Correspondence: xielin@jlu.edu.cn; Tel.: +86-431-8561-9455
}

check for updates

Citation: Tian, H.; Yu, H.; Lin, Y.; Li, Y.; Xu, W.; Chen, Y.; Liu, G.; Xie, L. Association between FADS Gene Expression and Polyunsaturated Fatty Acids in Breast Milk. Nutrients 2022, 14, 457. https://doi.org/ $10.3390 /$ nu14030457

Academic Editor: Hui-Lian Zhu

Received: 31 December 2021

Accepted: 17 January 2022

Published: 20 January 2022

Publisher's Note: MDPI stays neutral with regard to jurisdictional claims in published maps and institutional affiliations.

Copyright: (C) 2022 by the authors. Licensee MDPI, Basel, Switzerland. This article is an open access article distributed under the terms and conditions of the Creative Commons Attribution (CC BY) license (https:// creativecommons.org/licenses/by/ $4.0 /)$.

\begin{abstract}
Polyunsaturated fatty acid (PUFA) in breast milk provides physiological benefits for offspring and is closely related to endogenous biosynthesis in lactating women. Few studies have addressed the association between fatty acid desaturase (FADS) gene expression patterns and fatty acids in breast milk. This research aimed to explore the differences in PUFA levels among breast milk groups with different levels of FADS gene expression and provide a scientific basis for precision nutrition strategies. A total of 50 healthy women $42-45$ days postpartum were included in this study. A basic information questionnaire and breast milk samples were collected. Eight types of PUFA were detected, and RNA was extracted from breast milk. The transcription level of the FADS gene was detected using real-time quantitative PCR. Significant differences in the content of gamma-linolenic acid and eicosatrienoic acid (C20:3n6) were found in breast milk among FADS1 gene transcription groups ( $p=0.009, p=0.042$, respectively). No significant differences in PUFA were found among the FADS2 and FADS3 gene expression groups. The results demonstrated that $\mathrm{n}-6$ PUFA was associated with the mRNA expression levels of the FADS1 gene. They are of great significance in developing new methods and diets to optimize infant feeding using breast milk.
\end{abstract}

Keywords: breast milk; polyunsaturated fatty acid; FADS gene; gene expression

\section{Introduction}

Breast milk, known as "white blood", provides critical nutrients such as beneficial microbes, and it is an ideal food source for breastfeeding babies [1]. The macronutrients in human breast milk such as carbohydrates, proteins, and fats, are a source of energy, and approximately $50 \%$ of this energy is derived from fatty acids (FAs) [2]. Studies have shown that the macronutrients present in breast milk are relatively consistent among lactating women [3], while FA content varies greatly [2,4,5].

FAs in breast milk are classified into saturated FA (SFA), monounsaturated FA (MUFA), and polyunsaturated FA (PUFA) according to the number of unsaturated double bonds in their chemical structure. Furthermore, n-3-series and n-6-series FAs exist in PUFA according to the position of their unsaturated double bonds [6]. These three types of FAs play different roles in the body. Dietary SFA is a critical factor that seems to trigger alterations associated with the function of insulin resistance [7]. A diet rich in MUFA could reduce the number of established disease biomarkers in patients, as well as the incidence of coronary heart disease and type 2 diabetes [8]. In contrast, PUFA, in particular eicosapentaenoic acid (EPA) and docosahexaenoic acid (DHA), plays a beneficial physiological role in offspring receiving this FA during critical periods of development [9]. It is well known that DHA plays an important role in the growth and development of the brain and retina in infants [10-12]. 
EPA and DHA in breast milk also have beneficial effects on anti-inflammation [13], infant psychomotor development [14,15], and reduce the risk of childhood allergic disease [16].

Research shows that the postnatal development of an infant is strongly associated with the FA content of their mother's milk during lactation, and this FA profile may influence the individual risk of developing metabolic diseases throughout their life $[9,17]$. The World Health Organization pointed out that infants should be exclusively breastfed for more than 6 months from birth, and after 6 months, supplementary food may be added while maintaining breastfeeding until the age of 2 years old or more [18]. In addition, the first 2 years following birth represent a critical period for the development of the brain and retina in infants and young children [19]. PUFA in breast milk is the only dietary source for exclusively breastfeeding infants. Therefore, ensuring sufficient levels of PUFA in breast milk is essential for the long-term growth and physical health of babies.

A systematic review and meta-analysis indicated significant variation in the FA profiles in breast milk among different populations [20]. The intake of deep-sea fish and shrimp among inland lactating women was lower than that in mothers living in other areas. Therefore, their level of PUFA intake, as well as the content of DHA in their bodies, was lower [21]. Furthermore, in a population from the same area, the composition of PUFA in the breast milk of lactating women was closely related to endogenous biosynthesis in addition to dietary intake [22]. Thus, it is more critical to study the synthesis of PUFA in the bodies of lactating mothers living in inland areas where the dietary intake of fish is lower.

Two key enzymes are present in the bioconversion of the essential FAs linoleic acid (LA) and $\alpha$-linolenic acid (ALA) into longer-chain PUFA: $\Delta-5$ desaturase and $\Delta-6$ desaturase. $\triangle-5$ desaturase is encoded by the FADS1 gene, while the FADS2 gene is responsible for $\triangle-6$ desaturase. However, another FADS3 gene is located in the FADS gene cluster, and its function is uncertain [23]. Research on the association between PUFA and FADS gene expression has mainly focused on animals. In animal experiments, it was found that the mRNA expression levels of FADS1 and FADS2 genes in rats fed with lower PUFA levels were significantly increased [24]. Furthermore, most studies have been performed on human tissue derived from the blood and liver, while few studies have evaluated the association of breast milk composition in the context of the FADS gene [25,26]. FADS gene expression has tissue-specific effects [25], and it is necessary to study the relationship between PUFA and FADS gene expression in breast milk to understand PUFA regulation.

The cellular components of human milk offer the possibility to study the association between the expression of FADS gene clusters and PUFA constituents in breast milk [27]. In this study, fresh breast milk was used as the sample, and molecular biology technology was applied to detect the mRNA expression of the FADS gene cluster. This study focused on the association between FADS gene expression and PUFA profile in the milk of lactating mothers living in inland areas. We hypothesized that the higher the mRNA level of the FADS gene expressed among lactating women, the higher the proportion of PUFA contained in their breast milk. The purpose of this research was to explore the differences in PUFA levels in relation to different $F A D S$ gene expression groups and provide a scientific basis for optimizing the management of infant feeding.

\section{Materials and Methods}

\subsection{Participants}

This study was conducted from January 2017 to August 2017 and was a cross-sectional survey. Participants in this study were from a women and children health care hospital in Changchun City, Jilin Province, China, including a total of 50 Chinese Han lactating mothers 42-45 days postpartum. The eligibility criteria were: a healthy, breastfeeding woman without any diseases during pregnancy and lactation; not taking PUFA supplements after delivery; and a healthy, singleton infant with a gestational age of $\geq 37$ weeks and a weight $\geq 2500 \mathrm{~g}$. The study procedure was approved by the Ethics Committee of the School of Public Health, Jilin University, China (No. 2016-08-01). All mothers provided informed consent at the beginning of this research. 


\subsection{Breast Milk Collection and Questionnaires}

We collected breast milk samples from each volunteer by manual expression, and a total of $20 \mathrm{~mL}$ of breast milk was placed into two clean tubes between 9:00 and 11:00 a.m. One tube of breast milk was used to detect PUFA, while the other tube was used to extract RNA. All breast milk samples included mature milk and were quickly positioned in a $4{ }^{\circ} \mathrm{C}$ icebox. Samples were stored in a $-80{ }^{\circ} \mathrm{C}$ refrigerator, and detection took place within 2 weeks. A questionnaire was used to investigate each participant's basic information, and it was implemented through face-to-face interviews by trained investigators preceding milk collection.

\subsection{Fatty Acids Analysis}

PUFA in breast milk was detected using capillary gas chromatography, and the protocol of the experiment was described in detail in previous studies [28,29]. A total of eight types of PUFA in breast milk were detected, including four n-6 PUFA and four n-3 PUFA. The level of PUFA in breast milk was presented using the weight percentage of each FA in total FA.

\subsection{RNA Extraction}

The TRIzol method was used to extract total RNA from breast milk. The tubes containing $10 \mathrm{~mL}$ of breast milk were removed from the $-80^{\circ} \mathrm{C}$ freezer and thawed at room temperature. Liquid milk was immediately centrifuged at $4{ }^{\circ} \mathrm{C}$, and three liquid levels were clearly detected: the upper semifluid was the fat in breast milk, the intermediate liquid was skimmed breast milk, and the cells were at the bottom of the tube [30]. The precipitated cells were kept at the bottom of the tube, and $1 \mathrm{~mL}$ of phosphate-buffered saline (PBS) was added to the tube to wash them. Then, the PBS containing precipitated cells was transferred into a new $1.5 \mathrm{~mL}$ tube and centrifuged for $15 \mathrm{~min}$. The supernatant was discarded, and $1 \mathrm{~mL}$ of TRIzol reagent (Takara, Japan) was added to the tube containing the precipitate. Afterward, the tube was left at room temperature for $10 \mathrm{~min}$. Then, the mixture was centrifuged, and the supernatant was poured into a new tube.

A total of $400 \mu \mathrm{L}$ of chloroform was added to the supernatant, and the tube was capped and vigorously shaken for $30 \mathrm{~s}$. The next step involved centrifuging the mixture and transferring the supernatant to another new tube (about $500 \mu \mathrm{L}$ ). The same volume of isopropanol was added to the tube containing the supernatant, and it was mixed by turning it upside down and placed at room temperature for $30 \mathrm{~min}$. Then, the mixture was centrifuged, and the supernatant was discarded. With the RNA at the bottom of the tube, $1 \mathrm{~mL}$ of $75 \%$ ethanol in DEPC was added to wash the RNA sediment. Next, the tube was centrifuged at $4{ }^{\circ} \mathrm{C}$ and $8000 \times g$ for $5 \mathrm{~min}$, and the washing lipid was poured. A total of $10 \mu \mathrm{L}$ of RNAse-free water was added to dissolve the cleaned RNA after it was washed twice. Then, $1 \mu \mathrm{L}$ of RNA suspension was drafted on the nucleic acid quantifier to determine the concentration and purity of the extracted RNA. The 1\% agarose gel electrophoresis technique was used to detect the integrity of total RNA extracted from breast milk. cDNA was prepared using a transcription kit (Vazyme, Nanjing, China) according to the manufacturer's protocol.

\subsection{Quantitative Real-Time PCR}

The Fast Start Universal SYBR Green Master Mix (Roche) was used to carry out the quantitative real-time PCR experiment on the Agilent Stratagene MxPro system following the fast PCR protocol. The human glyceraldehyde 3-phosphate dehydrogenase (GAPDH) gene was selected as the internal reference for all analyses (No. B661104-0001, Sangon Biotech, Shanghai, China). Primers of FADS1, FADS2 and FADS3 genes were designed using NCBI Primer online, and the sequences are shown in Table 1. 
Table 1. Primer sequences of FADS genes used for quantitative RT-PCR amplification.

\begin{tabular}{ccc}
\hline Gene & Primer & Sequence $\mathbf{5}^{\prime} \rightarrow \mathbf{3}^{\prime}$ \\
\hline \multirow{2}{*}{ FADS1 } & Forward & GTGGC TAGTG ATCGA CCGTA A \\
& Reverse & ATTCT TGGTG GGCTC AAAGC \\
FADS2 & Forward & AACTG GTGGA ATCAT CGCCA \\
& Reverse & ATTCG CCCAG AACAA ACACG \\
FADS3 & Forward & TCGTG ATGGG GCAGC TAAAG \\
& Reverse & CTTCT TGCCA TACTC GACGG A \\
\hline
\end{tabular}

\subsection{Statistical Analysis}

The basic information questionnaire database was established using Epidata 3.0 software. The mean \pm standard deviation was used to express values of normally distributed data, the median (P25, P75) was used to express skewed data, and numbers (percentage) were used to express categorical data. SPSS Statistics software (version 24.0) and GraphPad Prism (version 7.0) were used to analyze the differences in PUFA levels in breast milk between different $F A D S$ gene transcription and translation groups. All statistical tests were two-tailed, and $p<0.05$ was considered significant.

\section{Results}

\subsection{Maternal Demographics of Participants}

The maternal and infant demographics are shown in Table 2. The mean age of the 50 lactating women was $29.58 \pm 2.42$ years, and more than half of the participants were from middle-income households $(52.00 \%)$. The mean preconception body mass index (BMI) of women was $20.68 \pm 2.85$, and they gained an average of $16.23 \pm 5.53 \mathrm{~kg}$ of weight during pregnancy. More than half $(52.00 \%)$ of the participants had a natural delivery. With respect to infants, their mean gestational age was $39.58 \pm 0.93$ weeks, and the mean birth weight was $3.45 \pm 0.49 \mathrm{~kg}$. A total of $72.00 \%$ of babies were exclusively breastfed, while the remaining received mixed feeding.

Table 2. Maternal and infant demographics of the participants.

\begin{tabular}{|c|c|}
\hline Characteristics & Mean \pm SD/N (\%) \\
\hline $\begin{array}{l}\text { Maternal age } \\
\text { (year) }\end{array}$ & $29.58 \pm 2.42$ \\
\hline Preconception BMI & $20.68 \pm 2.85$ \\
\hline $\begin{array}{l}\text { Gestational weight gain } \\
\qquad(\mathrm{kg})\end{array}$ & $16.23 \pm 5.53$ \\
\hline $\begin{array}{l}\text { Gestational age } \\
\text { (weeks) }\end{array}$ & $39.58 \pm 0.93$ \\
\hline $\begin{array}{l}\text { Birth weight } \\
(\mathrm{kg})\end{array}$ & $3.45 \pm 0.49$ \\
\hline $\begin{array}{l}\text { Birth length } \\
(\mathrm{cm})\end{array}$ & $50.59 \pm 1.26$ \\
\hline \multicolumn{2}{|l|}{ Family income (yuan/month) } \\
\hline$<5000$ & $9(18.00)$ \\
\hline 5000-9999 & $26(52.00)$ \\
\hline$\geq 10,000$ & $15(30.00)$ \\
\hline \multicolumn{2}{|l|}{ Mode of delivery } \\
\hline Vaginal & $26(52.00)$ \\
\hline Cesarean & $24(48.00)$ \\
\hline \multicolumn{2}{|l|}{ Feeding patterns } \\
\hline Breastfeeding & $36(72.00)$ \\
\hline Mixed feeding & $14(28.00)$ \\
\hline
\end{tabular}




\subsection{PUFA Profile of Breast Milk}

The average levels of eight types of PUFA in breast milk detected in this study are listed in Table 3, including four types of n-6-series PUFA and four of n-3-series PUFA. Among the n-6-series PUFA, arachidonic acid (AA) accounted for $0.8616 \%$ of the total FAs. Among the n-3-series PUFA, the contents of EPA and DHA in breast milk were $0.1097 \%$ and $0.2952 \%$, respectively.

Table 3. PUFA profile of breast milk in this study.

\begin{tabular}{cccc}
\hline Series & PUFA & & $\begin{array}{c}\text { Percentage of Total FA (\%) } \\
\text { (Mean } \pm \text { SD/Median (P25, P75)) }\end{array}$ \\
\hline $\mathrm{n}-6$ & Linoleic acid (LA) & $\mathrm{C} 18: 2 \mathrm{n} 6$ & $21.0886 \pm 4.7437$ \\
& $\gamma$-Linolenic acid & $\mathrm{C} 18: 3 \mathrm{n} 6$ & $0.3245 \pm 0.1008$ \\
& Eicosatrienoic acid & $\mathrm{C} 20: 3 \mathrm{n} 6$ & $0.4726 \pm 0.1245$ \\
$\mathrm{n}-3$ & Arachidonic acid (AA) & $\mathrm{C} 20: 4 \mathrm{n} 6$ & $0.8616 \pm 0.1996$ \\
& $\alpha$-Linolenic acid (ALA) & $\mathrm{C} 18: 3 \mathrm{n} 3$ & $1.9504(1.4444,2.7370)$ \\
& Eicosatrienoic acid & $\mathrm{C} 20: 3 \mathrm{n} 3$ & $0.0999 \pm 0.0320$ \\
& Eicosapentaenoic acid (EPA) & $\mathrm{C} 20: 5 \mathrm{n} 3$ & $0.1097(0.0787,0.1499)$ \\
& Docosahexaenoic acid (DHA) & $\mathrm{C} 22: 6 \mathrm{n} 3$ & $0.2952 \pm 0.1114$ \\
\hline
\end{tabular}

\subsection{Groups Divided by the mRNA Expression of FADS Gene}

Groups were divided based on the median of mRNA relative expression levels among different isoforms of FADS genes, and depending on the expression level of each FADS gene, two more groups were created, as shown in Table 4. mRNA Q1 represents the low mRNA expression group, and mRNA Q2 represents the high mRNA expression group of each FADS gene. The expression of the three FADS genes was significantly different between groups $(p<0.001)$.

Table 4. Relative levels of mRNA and groups divided by expression of FADS genes.

\begin{tabular}{ccccc}
\hline \multirow{2}{*}{ Gene } & \multirow{2}{*}{$\begin{array}{c}\text { Relative Level of mRNA } \\
\text { Median (P25, P75) }\end{array}$} & mRNA Q1 & \multirow{2}{*}{ mRNA Q2 } \\
\cline { 2 - 4 } & & $\leq-0.1302$ & $>-0.1302$ & $<0.001$ \\
\hline FADS1 & $-0.1302(-0.1319,-0.1255)$ & $\leq-0.2619$ & $>-0.2619$ & $<0.001$ \\
FADS2 & $-0.2619(-0.3497,-0.1359)$ & $\leq-0.5039$ & $>-0.5039$ & $<0.001$ \\
FADS3 & $-0.5039(-0.8220,-0.0132)$ & & \\
\hline
\end{tabular}

\section{4. n-6 PUFA and the mRNA Expression of FADS Gene}

The association between the mRNA expression of the FADS gene and four types of n-6 PUFA is shown in Figure 1. The amount of LA (C18:2n6) exhibited no differences among the mRNA expression groups of the FADS1, FADS2, and FADS3 genes (Figure 1A). However, there were significant differences in $\gamma$-linolenic acid (C18:3n6) and eicosatrienoic acid (C20:3n6) among the FADS1 gene mRNA groups ( $p=0.009, p=0.042$, respectively). Furthermore, the level of $\gamma$-linolenic acid (C18:3n6) in FADS1 mRNA group Q2 (0.3606\%) was higher than that in FADS1 mRNA group Q1 (0.2869\%), which was also the case for eicosatrienoic acid (C20:3n6, Q1:0.5088\% vs. Q2:0.4363\%). No significant differences in these two types of n-6 PUFA were observed between the FADS2 and FAD3 groups (Figure 1B,C). Furthermore, no statistically significant differences were found in the proportion of AA (C20:4n6) in breast milk among FADS gene expression groups (Figure 1D). 
A

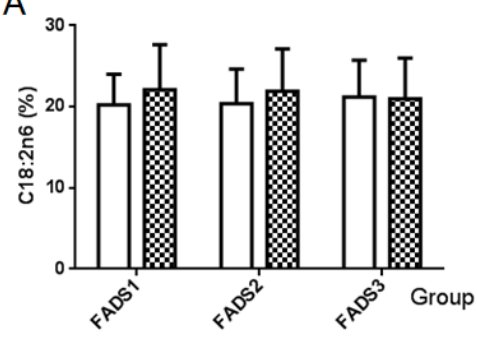

C

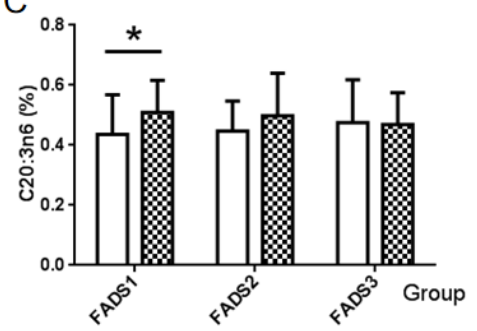

$B$

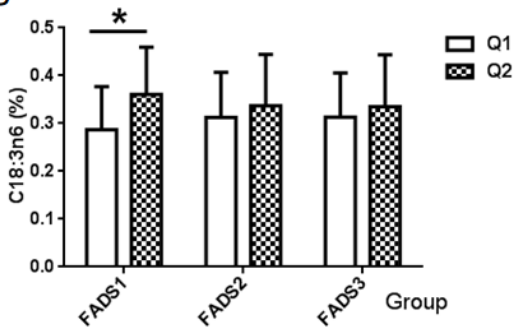

D

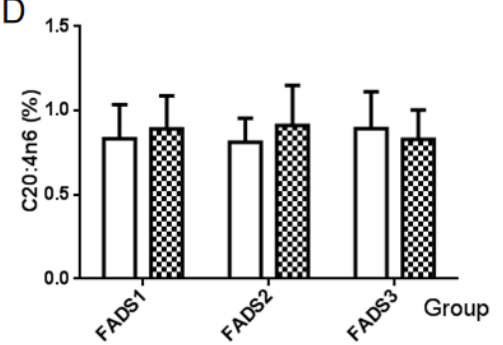

Figure 1. Association between the n-6 PUFA and mRNA expression groups of FADS genes. Values are the proportion of each n-6 PUFA of breast milk among FADS gene expression groups. (A) $\alpha$-Linoleic acid (C18:2n6), (B) $\gamma$-linolenic acid (C18:3n6), (C) eicosatrienoic acid (C20:3n6), and (D) arachidonic acid AA (C20:4n6). * $p<0.05$, Q1: Low mRNA expression group, Q2: High mRNA expression group.

\section{5. n-3 PUFA and the mRNA Expression of FADS Gene}

The percentage of four types of n-3 PUFA in breast milk among the mRNA expression groups of the FADS gene is summarized in Figure 2. No significant differences were observed in all n-3 PUFA among FADS gene expression groups, including $\alpha$-linolenic acid (C18:3n3), eicosatrienoic acid (C20:3n3), EPA (C20:5n3), and DHA (C22:6n3).

A

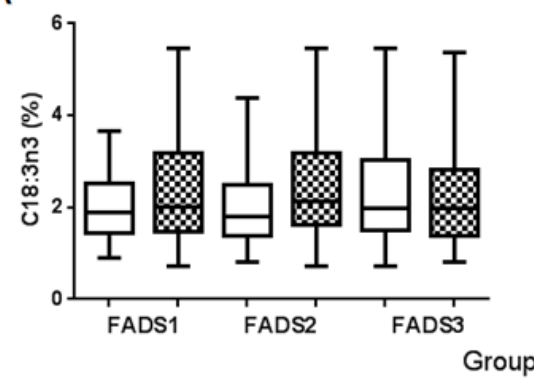

C

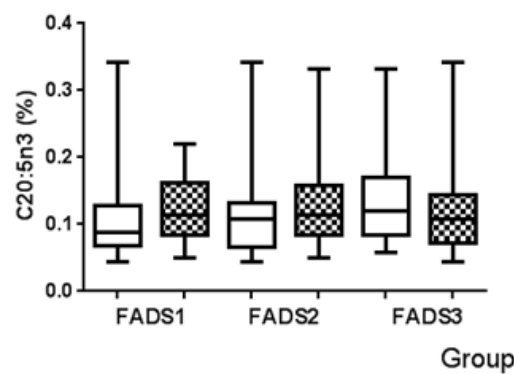

B
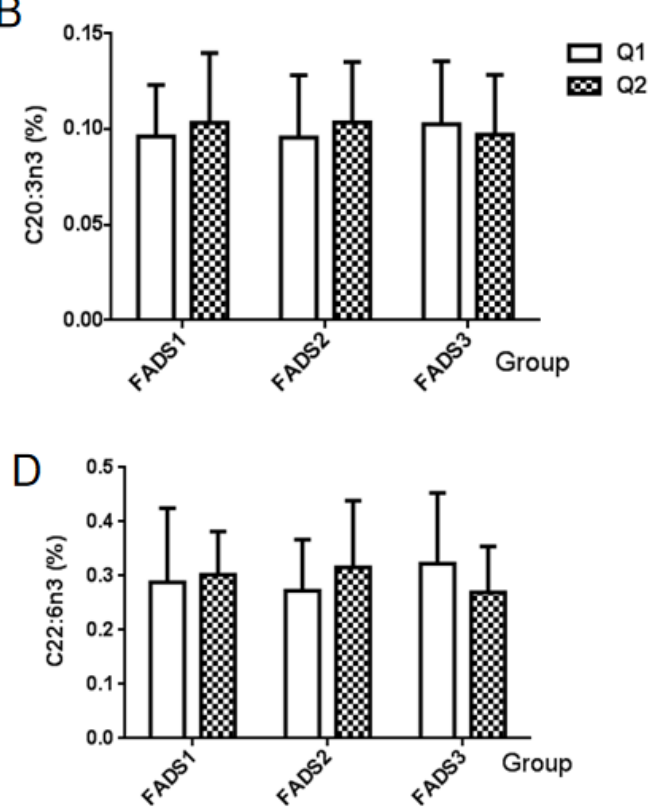

Figure 2. Association between the n-3 PUFA and mRNA expression groups of FADS genes. Values are the proportion of each n-3 PUFA of breast milk among FADS gene expression groups. (A) $\alpha$-Linolenic acid (C18:3n3), (B) eicosatrienoic acid (C20:3n3), (C) EPA (C20:5n3), and (D) DHA (C22:6n3). Q1: Low mRNA expression group, Q2: High mRNA expression group. 


\subsection{Enzyme Activity and PUFA Pathway Activity}

Enzyme activity and PUFA pathway activity could be evaluated using the ratios between the product and precursor FA in breast milk. Enzyme activity included $\Delta-5$ desaturase and $\Delta-6$ desaturase activities, while PUFA pathway activity consisted of n-3 PUFA pathway and n-6 PUFA pathway activities. Calculation formulas [31] and proportions of these four indexes are summarized in Table 5 . In this study, the proportion of $\Delta-5$ desaturase activity was 1.8482 , and that of $\Delta-6$ desaturase activity was 0.0154 ; the n-3 PUFA pathway was 0.0554 , and the n-6 PUFA pathway was 0.0418. Distributions of the four indexes among FADS gene expression groups are shown in Figure 3. No significant differences were observed in neither desaturase activity (Figure 3A,B) nor in the two PUFA pathways (Figure 3C,D).

Table 5. Indexes of PUFA with breast milk in this study.

\begin{tabular}{ccc}
\hline Index & Calculation Formula & Mean \pm SD/Median (P25, P75) \\
\hline D5D $^{*}$ & C20:4n6/C20:3n6 & $1.8482 \pm 0.5725$ \\
D6D $^{*}$ & C18:3n6/C18:2n6 & $0.0154(0.0127,0.0190)$ \\
n-3 pathway & C20:5n3/C18:3n3 & $0.0554(0.0303,0.0798)$ \\
n-6 pathway & C20:4n6/C18:2n6 & $0.0418(0.0354,0.0481)$ \\
\hline
\end{tabular}

${ }^{*}$ D5D: $\Delta-5$ desaturase activity; D6D: $\Delta-6$ desaturase activity.

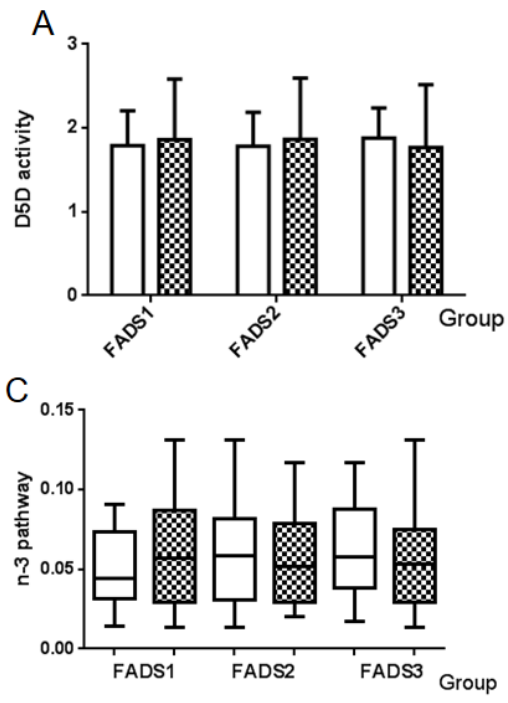

B
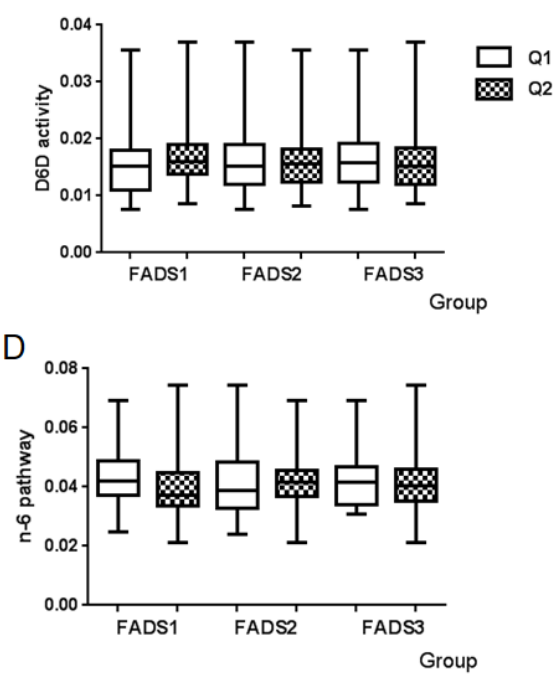

Figure 3. Distributions of enzyme activity and PUFA pathway activity among FADS gene expression groups. (A) D5D activity, (B) D6D activity, (C) n-3 PUFA pathway, and (D) n-6 PUFA pathway. Q1: Low mRNA expression group, Q2: High mRNA expression group.

\section{Discussion}

A total of 50 lactating women 42 to 45 days postpartum were enrolled in our study. Breast milk was collected to detect the FA profile and PUFA content. Moreover, the experimental protocol of RNA extraction from breast milk was established in this study. Furthermore, the mRNA expression levels in human milk among three FADS gene groups were detected by using the molecular biological technique. We conducted this study to explore whether the mRNA expression among FADS genes affects PUFA content of breast milk.

The average content of DHA in the breast milk of the participants included in this study was $0.2952 \%$, which was lower than the corresponding global average content of $0.32 \%$ [32]. One of the main reasons for this observation is that Changchun City is located in the inlands of northeast China, and the intake of deep-water fish among lactating women 
is lower than that in the mothers from coastlands [21]. This led to the lower DHA content in breast milk in this study, while it was similar to that in $0.30 \%$ of the mothers from the North European country Latvia, where the consumption of fish among lactating women is low [33]. However, the average DHA content in breast milk in this research was lower than the average content of DHA in two populations of lactating women from China $(0.36 \%)$ and Korea $(0.67 \%)$ [21,34]. Furthermore, the average content of EPA in our study was $0.1097 \%$, and it was also lower than that in Korean participants. The most probable reason for this result is that the breastfeeding women enrolled in this study were not taking PUFA supplements during lactation. Since PUFA supplements could affect the activity of key enzymes in PUFA metabolic pathways $[35,36]$, participants who did not take PUFA supplements could rule out the effect of dietary supplements on the gene expression of key enzymes and provide better foundations for research on the relationship between breast milk PUFA and FADS gene expression. The average content of AA was the opposite to that of DHA and AA in breast milk in this study, and it was $0.8616 \%$ of the total FA and higher than that in Korean mothers $(0.48 \%)$. It was also higher than the global average content $(0.71 \%)$. One of the reasons might be that the main source of AA in the body is the conversion of its precursor substance LA, while the main source of LA in the lactating woman body is the plant-sourced oils, such as corn and peanut oils. The amount of plant-sourced oil intake among Chinese lactating women is high due to traditional cooking [37]. The large LA intake, together with n-6 PUFA derived from LA, could contribute to the high level of LA in the body, which competes with key enzymes of FA-synthesizing pathways; thus, inhibiting precursor substance of n-3 PUFA derivative for EPA and DHA [38]. Therefore, the high level of LA in the body among lactating women results in the high level of LA with n-6 PUFA derived from LA in their milk, which reduces the DHA concentration in breast milk. Therefore, the high percentage of AA in this study might be associated with the low EPA and DHA in breast milk [39].

Recent research has shown an association between FADS genes and FA desaturase activities [31]. We focused on four indexes to clarify the correlation between FADS gene expression and FA metabolism in breast milk. The four indexes of breast milk included $\Delta-5$ FA desaturase and $\Delta-6$ FA desaturase activities, as well as n-3 PUFA pathway and n-6 PUFA pathway activities. In our study, the level of $\Delta-5$ FA desaturase activity was 1.8482 , and that of $\Delta-6$ FA desaturase activity was 0.0154 . Few studies have focused on FA desaturase activity and PUFA pathway activity in breast milk. Research on FA desaturase activity in human plasma showed that the level of $\Delta-5$ desaturase activity was 4.39 , and that of $\Delta-6$ desaturase activity was 0.0016 [40]. This indicates that the level of $\Delta-6$ FA desaturase activity in breast milk in this study is similar to that of $\Delta-6$ desaturase activity in plasma, while the level of $\Delta-5$ FA desaturase activity in breast milk is lower than that in plasma. The average level of n-3 PUFA pathway activity was 0.0554 , and that of n-6 PUFA pathway activity was 0.0418 in breast milk in our study. n-3 PUFA pathway activity is $0.842-1.001$, and that of n-6 PUFA pathway activity is 0.233-0.389 in plasma. These results suggest the two PUFA pathway activities in human milk might be lower than those in plasma [31].

In the evaluation of the association between the PUFA of breast milk and the mRNA expression among FADS genes, we found that two types of n-6 PUFA were associated with the mRNA expression of the FADS1 gene. GLA and eicosatrienoic acid (C20:3n6) in breast milk in the high mRNA FADS1 gene expression group were higher than those in the other group. LA is the essential FA ingested from food, and it is the precursor substance for AA biosynthesis in our body. As a consequence, the LA proportion of breast milk is mainly derived from the food intake of lactating mothers. No significant differences in LA in breast milk among the mRNA expression groups of the three FADS genes demonstrated the consistent amount of LA sourced food intake among our participants. A recent study showed that LA content in the breast milk of Chinese mothers was positively correlated with the consumption of soybeans and soybean products [37]. According to a previous dietary survey by our research team [41], the amount of dietary intake LA was higher than its adequate intake [42]. Consequently, the amount of LA from dietary intake is 
sufficient to meet the level of LA in breast milk that satisfies the demands of infant growth and development.

The higher percentage of GLA in breast milk in the high FADS1 gene $m R N A$ expression group might be related to the higher level of transcription regulation of the FADS1 gene among lactating women. Research demonstrated that the demand for PUFA was increased during pregnancy and lactation in women; thus, the dietary intake of FA by the mothers could activate the mechanism of gene transcription. Dietary PUFA and its metabolites act on the cellular nucleus level and regulate the mRNA expression of the FADS gene together with transcription factors [24]. An animal study indicated that suckling piglets that suckled milk from LA-supplemented sows showed increased mRNA expression levels of genes than those that suckled milk from palmitic acid-supplemented sows during gestation to weaning [43]. This study made it abundantly clear that dietary n-6-series PUFA intake was related to the mRNA level of gene expression.

Another study on rats showed significant overexpression of FADS1 and FADS2 mRNA during pregnancy and lactation in the breast, liver, and adipose tissues in low lipid diet fed rats compared with those fed an appropriate lipid diet [44]. The result of this research seems to contradict that of our study; however, it has been shown that lactating mothers have higher levels of LA intake based on previous studies in this article, which exceed the recommended intake level. Therefore, we conclude that when the level of the substrate LA in the body is higher, it could fully combine with key enzymes in pathways of PUFA metabolism and promote the downward conversion of the substrate LA to GLA, with the final product being AA. Gene expression plays a relatively small role when the dietary intake of lactating women is high. Consequently, there was no difference in the amount of AA in breast milk in this study among the mRNA expression groups of the three FADS genes. While the limited number of key enzymes was combined with enough substrate, the insufficient amounts of enzymes might promote the increase in the mRNA expression level of the FADS gene that synthesizes the key enzymes. Therefore, the higher percentage of GLA and eicosatrienoic acid (C20:3n6) in the high FADS1 gene mRNA expression group might be affected by the interaction between maternal gene expression and dietary intake [45]. Once a certain level of the substrate AA is produced, a negative feedback regulation may occur. $\triangle-5$ desaturase encoded by the FADS1 gene is located closer to the substrate AA in the PUFA conversion pathway, while $\Delta-6$ desaturase encoded by the FADS2 gene is located farther away from the substrate AA [46]. The high level of substrate AA might inhibit the expression of FADS1 genes that are closer to AA. Therefore, we only found the difference in the two types of n-6 PUFA intermediate products between the mRNA expression groups of the FADS1 gene, while we did not find such a difference between the mRNA expression groups of the FADS2 gene. We did not detect the association between any mRNA expression groups of FADS genes and n-3-series PUFA in this study. We infer that n-3 PUFA might be related to the protein expression level of the FADS gene cluster, and future studies need to verify our inference. There were no associations between FADS3 gene expression and PUFA in breast milk in our study, and the function of the FADS3 gene in relation to PUFA synthesis needs to be addressed in future studies $[47,48]$.

We used human milk as the sample in this study to detect the association between mRNA expression of FADS genes and PUFA profiles in breast milk. The result of our study demonstrated that n-6 PUFA was associated with the mRNA expression levels of the FADS1 gene. To our knowledge, this is the first research in China to find the association between FADS gene expression and the PUFA in the breast milk of lactating mothers. While this study is innovative, it also has limitations. We did not collect the data on the dietary background of PUFA levels in the 50 lactating mothers. We only focused on the relationship between the level of PUFA and the FADS gene expression in breast milk, because it was impossible to evaluate the combined effect of maternal dietary intake and FADS gene expression on the PUFA profile in breast milk. According to the previous dietary survey by our research team on the maternal PUFA intake, we found that the intake of the essential FAs LA and ALA by lactating mothers far exceeded the reference intake, while that of EPA 
and DHA was far below the reference intake among our participants. However, the lack of differences in the content of these FAs among FADS gene mRNA expression groups indicated that the dietary intake in lactating women is relatively consistent. Therefore, the dietary PUFA in the included 50 lactating women might not have a significant impact on the results of this study. Furthermore, the milk samples analyzed in this study were collected from the 50 lactating women who were $42-45$ days postpartum, which failed to reach the sample size for detecting genetic variants of some key single-nucleotide polymorphisms (SNPs) [22,28,49-51]. As a result, we could not combine FADS gene variants with their gene expression patterns and the PUFA profile in breast milk. A study has shown that FADS1 gene polymorphism could regulate gene transcription in human liver tissue, thereby changing the composition of FA in the liver [52]. In our future studies, we shall continue to collect participants to reach the relevant number of samples necessary to detect key SNPs of FADS genes associated with PUFA profiles in breast milk to clarify the role of different SNP genotypes in FADS gene expression. Our study will provide a basis for guiding individual breastfeeding mothers with different genotypes to nurture infants scientifically and contribute to precision nutrition strategies.

Author Contributions: Conceptualization, H.T. and L.X.; methodology, Y.L. (Yiqi Lin); software, H.Y.; validation, Y.L. (Yueting Li), W.X. and Y.C.; formal analysis, H.Y.; investigation, Y.L. (Yueting Li); resources, G.L.; data curation, W.X.; writing—original draft preparation, H.T.; writing-review and editing, L.X.; visualization, Y.L. (Yiqi Lin); supervision, H.T.; project administration, L.X.; funding acquisition, Y.L. (Yiqi Lin). All authors have read and agreed to the published version of the manuscript.

Funding: This research was funded by the Health Commission of Jilin Province (Grant No. 2021JC042) and the Education Department of Jilin Province (Grant No. JJKH20221101KJ).

Institutional Review Board Statement: The study was conducted in accordance with the Declaration of Helsinki and approved by the Ethics Committee of the School of Public Health, Jilin University, China (No. 2016-08-01; Date of Approval, 19 August 2016).

Informed Consent Statement: Informed consent was obtained from all subjects involved in the study.

Data Availability Statement: All the data of our research are reported in this manuscript, and they are available from the corresponding author.

Acknowledgments: We would thank all the mothers who contributed breast milk to our study.

Conflicts of Interest: The authors declare no conflict of interest.

\section{References}

1. Lyons, K.E.; Ryan, C.A.; Dempsey, E.M.; Ross, R.P.; Stanton, C. Breast milk, a source of beneficial microbes and associated benefits for infant health. Nutrients 2020, 12, 1039. [CrossRef]

2. Miliku, K.; Duan, Q.L.; Moraes, T.J.; Becker, A.B.; Mandhane, P.J.; Turvey, S.E.; Lefebvre, D.L.; Sears, M.R.; Subbarao, P.; Field, C.J.; et al. Human milk fatty acid composition is associated with dietary, genetic, sociodemographic, and environmental factors in the CHILD Cohort Study. Am. J. Clin. Nutr. 2019, 110, 1370-1383. [CrossRef]

3. Keikha, M.; Bahreynian, M.; Saleki, M.; Kelishadi, R. Macro- and micronutrients of human milk composition: Are they related to maternal diet? A comprehensive systematic review. Breastfeed. Med. 2017, 12, 517-527. [CrossRef]

4. Bravi, F.; Wiens, F.; Decarli, A.; Dal Pont, A.; Agostoni, C.; Ferraroni, M. Impact of maternal nutrition on breast-milk composition: A systematic review. Am. J. Clin. Nutr. 2016, 104, 646-662. [CrossRef]

5. Innis, S.M. Impact of maternal diet on human milk composition and neurological development of infants. Am. J. Clin. Nutr. 2014, 99, 734S-741S. [CrossRef]

6. Andreas, N.J.; Kampmann, B.; Mehring, L.K. Human breast milk: A review on its composition and bioactivity. Early Hum. Dev. 2015, 91, 629-635. [CrossRef] [PubMed]

7. Koska, J.; Ozias, M.K.; Deer, J.; Kurtz, J.; Salbe, A.D.; Harman, S.M.; Reaven, P.D. A human model of dietary saturated fatty acid induced insulin resistance. Metabolism 2016, 65, 1621-1628. [CrossRef] [PubMed]

8. Abdullah, M.M.; Jew, S.; Jones, P.J. Health benefits and evaluation of healthcare cost savings if oils rich in monounsaturated fatty acids were substituted for conventional dietary oils in the United States. Nutr. Rev. 2017, 75, 163-174. [CrossRef]

9. Mennitti, L.V.; Oliveira, J.L.; Morais, C.A.; Estadella, D.; Oyama, L.M.; Oller, D.N.C.; Pisani, L.P. Type of fatty acids in maternal diets during pregnancy and/or lactation and metabolic consequences of the offspring. J. Nutr. Biochem. 2015, $26,99-111$. [CrossRef] [PubMed] 
10. Mun, J.G.; Legette, L.L.; Ikonte, C.J.; Mitmesser, S.H. Choline and DHA in maternal and infant nutrition: Synergistic implications in brain and eye health. Nutrients 2019, 11, 1125. [CrossRef] [PubMed]

11. Richard, C.; Calder, P.C. Docosahexaenoic acid. Adv. Nutr. 2016, 7, 1139-1141. [CrossRef] [PubMed]

12. Calder, P.C. Docosahexaenoic acid. Ann. Nutr. Metab. 2016, 69, 7-21. [CrossRef] [PubMed]

13. Calder, P.C. Eicosapentaenoic and docosahexaenoic acid derived specialised pro-resolving mediators: Concentrations in humans and the effects of age, sex, disease and increased omega-3 fatty acid intake. Biochimie 2020, 178, 105-123. [CrossRef] [PubMed]

14. Zielinska, M.A.; Hamulka, J.; Grabowicz-Chadrzynska, I.; Brys, J.; Wesolowska, A. Association between breastmilk LC PUFA, carotenoids and psychomotor development of exclusively breastfed infants. Int. J. Environ. Res. Public Health 2019, $16,1144$. [CrossRef]

15. Shulkin, M.; Pimpin, L.; Bellinger, D.; Kranz, S.; Fawzi, W.; Duggan, C.; Mozaffarian, D. n-3 fatty acid supplementation in mothers, preterm infants, and term infants and childhood psychomotor and visual development: A systematic review and meta-analysis J. Nutr. 2018, 148, 409-418. [CrossRef]

16. Miles, E.A.; Calder, P.C. Can early omega-3 fatty acid exposure reduce risk of childhood allergic disease? Nutrients 2017, 9 , 784. [CrossRef]

17. Silva-Zolezzi, I.; Samuel, T.M.; Spieldenner, J. Maternal nutrition: Opportunities in the prevention of gestational diabetes. Nutr Rev. 2017, 75, 32-50. [CrossRef]

18. World Health Organization. Infant and Young Child Feeding; World Health Organization: Geneva, Switzerland, 2009.

19. Lauritzen, L.; Hansen, H.S.; Jorgensen, M.H.; Michaelsen, K.F. The essentiality of long chain n-3 fatty acids in relation to development and function of the brain and retina. Prog. Lipid Res. 2001, 40,1-94. [CrossRef]

20. Bahreynian, M.; Feizi, A.; Kelishadi, R. Is fatty acid composition of breast milk different in various populations? A systematic review and meta-analysis. Int. J. Food Sci. Nutr. 2020, 71, 909-920. [CrossRef]

21. Liu, M.J.; Li, H.T.; Yu, L.X.; Xu, G.S.; Ge, H.; Wang, L.L.; Zhang, Y.L.; Zhou, Y.B.; Li, Y.; Bai, M.X.; et al. A correlation study of DHA dietary intake and plasma, erythrocyte and breast milk DHA concentrations in lactating women from Coastland, Lakeland, and Inland areas of China. Nutrients 2016, 8, 312. [CrossRef] [PubMed]

22. Gonzalez-Casanova, I.; Rzehak, P.; Stein, A.D.; Garcia, F.R.; Rivera, D.J.; Barraza-Villarreal, A.; Demmelmair, H.; Romieu, I.; Villalpando, S.; Martorell, R.; et al. Maternal single nucleotide polymorphisms in the fatty acid desaturase 1 and 2 coding regions modify the impact of prenatal supplementation with DHA on birth weight. Am. J. Clin. Nutr. 2016, 103, 1171-1178. [CrossRef]

23. Blanchard, H.; Legrand, P.; Pedrono, F. Fatty acid desaturase 3 (Fads3) is a singular member of the Fads cluster. Biochimie 2011, 93 , 87-90. [CrossRef]

24. Sosa-Castillo, E.; Rodriguez-Cruz, M.; Molto-Puigmarti, C. Genomics of lactation: Role of nutrigenomics and nutrigenetics in the fatty acid composition of human milk. Br. J. Nutr. 2017, 118, 161-168. [CrossRef] [PubMed]

25. Reynolds, L.M.; Howard, T.D.; Ruczinski, I.; Kanchan, K.; Seeds, M.C.; Mathias, R.A.; Chilton, F.H. Tissue-specific impact of FADS cluster variants on FADS1 and FADS2 gene expression. PLoS ONE 2018, 13, e194610. [CrossRef]

26. Li, P.; Zhao, J.; Kothapalli, K.; Li, X.; Li, H.; Han, Y.; Mi, S.; Zhao, W.; Li, Q.; Zhang, H.; et al. A regulatory insertion-deletion polymorphism in the FADS gene cluster influences PUFA and lipid profiles among Chinese adults: A population-based study. Am. J. Clin. Nutr. 2018, 107, 867-875. [CrossRef] [PubMed]

27. Vass, R.A.; Kemeny, A.; Dergez, T.; Ertl, T.; Reglodi, D.; Jungling, A.; Tamas, A. Distribution of bioactive factors in human milk samples. Int. Breastfeed. J. 2019, 14, 9. [CrossRef]

28. Ding, Z.; Liu, G.L.; Li, X.; Chen, X.Y.; Wu, Y.X.; Cui, C.C.; Zhang, X.; Yang, G.; Xie, L. Association of polyunsaturated fatty acids in breast milk with fatty acid desaturase gene polymorphisms among Chinese lactating mothers. Prostaglandins Leukot. Essent. Fat. Acids 2016, 109, 66-71. [CrossRef]

29. Tian, H.M.; Wu, Y.X.; Lin, Y.Q.; Chen, X.Y.; Yu, M.; Lu, T.; Xie, L. Dietary patterns affect maternal macronutrient intake levels and the fatty acid profile of breast milk in lactating Chinese mothers. Nutrition 2019, 58, 83-88. [CrossRef]

30. Alsaweed, M.; Hepworth, A.R.; Lefevre, C.; Hartmann, P.E.; Geddes, D.T.; Hassiotou, F. Human milk microRNA and total RNA differ depending on milk fractionation. J. Cell. Biochem. 2015, 116, 2397-2407. [CrossRef]

31. Huang, M.C.; Chang, W.T.; Chang, H.Y.; Chung, H.F.; Chen, F.P.; Huang, Y.F.; Hsu, C.C.; Hwang, S.J. FADS gene polymorphisms, fatty acid desaturase activities, and HDL-C in type 2 diabetes. Int. J. Environ. Res. Public Health 2017, 14, 572. [CrossRef] [PubMed]

32. Juber, B.A.; Jackson, K.H.; Johnson, K.B.; Harris, W.S.; Baack, M.L. Breast milk DHA levels may increase after informing women: A community-based cohort study from South Dakota USA. Int. Breastfeed. J. 2016, 12, 7. [CrossRef]

33. Aumeistere, L.; Ciprovica, I.; Zavadska, D.; Volkovs, V. Fish intake reflects on DHA level in breast milk among lactating women in Latvia. Int. Breastfeed. J. 2018, 13, 33. [CrossRef]

34. Kim, H.; Kang, S.; Jung, B.M.; Yi, H.; Jung, J.A.; Chang, N. Breast milk fatty acid composition and fatty acid intake of lactating mothers in South Korea. Br. J. Nutr. 2017, 117, 556-561. [CrossRef] [PubMed]

35. Meldrum, S.J.; Li, Y.; Zhang, G.; Heaton, A.; D’Vaz, N.; Manz, J.; Reischl, E.; Koletzko, B.V.; Prescott, S.L.; Simmer, K. Can polymorphisms in the fatty acid desaturase (FADS) gene cluster alter the effects of fish oil supplementation on plasma and erythrocyte fatty acid profiles? An exploratory study. Eur. J. Nutr. 2018, 57, 2583-2594. [CrossRef] [PubMed]

36. Fernandez, M.L.; Blomquist, S.A.; Hallmark, B.; Chilton, F.H. Omega-3 supplementation and heart disease: A population-based diet by gene analysis of clinical trial outcomes. Nutrients 2021, 13, 2154. [CrossRef] [PubMed] 
37. Wu, W.; Balter, A.; Vodsky, V.; Odetallh, Y.; Ben-Dror, G.; Zhang, Y.; Zhao, A. Chinese breast milk fat composition and its associated dietary factors: A pilot study on lactating mothers in Beijing. Front. Nutr. 2021, 8, 606950. [CrossRef]

38. Chilton, F.H.; Dutta, R.; Reynolds, L.M.; Sergeant, S.; Mathias, R.A.; Seeds, M.C. Precision nutrition and omega-3 polyunsaturated fatty acids: A case for personalized supplementation approaches for the prevention and management of human diseases. Nutrients 2017, 9, 1165. [CrossRef]

39. Fu, Y.; Liu, X.; Zhou, B.; Jiang, A.C.; Chai, L. An updated review of worldwide levels of docosahexaenoic and arachidonic acid in human breast milk by region. Public Health Nutr. 2016, 19, 2675-2687. [CrossRef]

40. Al-Hilal, M.; Alsaleh, A.; Maniou, Z.; Lewis, F.J.; Hall, W.L.; Sanders, T.A.; O'Dell, S.D. Genetic variation at the FADS1-FADS2 gene locus influences delta-5 desaturase activity and LC-PUFA proportions after fish oil supplement. J. Lipid Res. 2013, 54, 542-551. [CrossRef] [PubMed]

41. Liu, G.; Ding, Z.; Li, X.; Chen, X.; Wu, Y.; Xie, L. Relationship between polyunsaturated fatty acid levels in maternal diets and human milk in the first month post-partum. J. Hum. Nutr. Diet. 2016, 29, 405-410. [CrossRef]

42. Chinese Nutrition Society. Chinese Dietary Reference Intakes; China Science Publishing: Beijing, China, 2014 ; pp. 77-161.

43. Lu, Z.Q.; Ren, Y.; Zhou, X.H.; Yu, X.F.; Huang, J.; Yu, D.Y.; Wang, X.X.; Wang, Y.Z. Maternal dietary linoleic acid supplementation promotes muscle fibre type transformation in suckling piglets. J. Anim. Physiol. Anim. Nutr. 2017, 101, 1130-1136. [CrossRef] [PubMed]

44. Rodriguez-Cruz, M.; Sanchez, R.; Sanchez, A.M.; Kelleher, S.L.; Sanchez-Munoz, F.; Maldonado, J.; Lopez-Alarcon, M. Participation of mammary gland in long-chain polyunsaturated fatty acid synthesis during pregnancy and lactation in rats. Biochim. Biophys. Acta 2011, 1811, 284-293. [CrossRef]

45. Mathias, R.A.; Pani, V.; Chilton, F.H. Genetic variants in the FADS gene: Implications for dietary recommendations for fatty acid intake. Curr. Nutr. Rep. 2014, 3, 139-148. [CrossRef]

46. Koletzko, B.; Reischl, E.; Tanjung, C.; Gonzalez-Casanova, I.; Ramakrishnan, U.; Meldrum, S.; Simmer, K.; Heinrich, J.; Demmelmair, H. FADS1 and FADS2 polymorphisms modulate fatty acid metabolism and dietary impact on health. Annu. Rev. Nutr. 2019, 39, 21-44. [CrossRef]

47. Yang, H.T.; Wang, R.Y.; Huang, S.Y.; Huang, C.L.; Su, K.P. Genetic polymorphisms of FADS1, FADS2, and FADS3 and fatty acid profiles in subjects received methadone maintenance therapy. Prostaglandins Leukot. Essent. Fatty Acids 2018, 136, 117-121. [CrossRef]

48. Bernard, J.Y.; Pan, H.; Aris, I.M.; Moreno-Betancur, M.; Soh, S.; Yap, F.; Tan, K.H.; Shek, L.P.; Chong, Y.; Gluckman, P.D.; et al Long-chain polyunsaturated fatty acids, gestation duration, and birth size: A Mendelian randomization study using fatty acid desaturase variants. Am. J. Clin. Nutr. 2018, 108, 92-100. [CrossRef] [PubMed]

49. Schuchardt, J.P.; Kobe, T.; Witte, V.; Willers, J.; Gingrich, A.; Tesky, V.; Pantel, J.; Rujescu, D.; Illig, T.; Floel, A.; et al. Genetic variants of the FADS gene cluster are associated with erythrocyte membrane LC PUFA levels in patients with mild cognitive impairment. J. Nutr. Health Aging 2016, 20, 611-620. [CrossRef] [PubMed]

50. Panda, C.; Varadharaj, S.; Voruganti, V.S. PUFA, genotypes and risk for cardiovascular disease. Prostaglandins Leukot. Essent. Fatty Acids 2021, 176, 102377. [CrossRef] [PubMed]

51. Xie, L.; Innis, S.M. Genetic variants of the FADS1 FADS2 gene cluster are associated with altered (n-6) and (n-3) essential fatty acids in plasma and erythrocyte phospholipids in women during pregnancy and in breast milk during lactation. J. Nutr. 2008, 138, 2222-2228. [CrossRef]

52. Wang, L.; Athinarayanan, S.; Jiang, G.; Chalasani, N.; Zhang, M.; Liu, W. Fatty acid desaturase 1 gene polymorphisms control human hepatic lipid composition. Hepatology 2015, 61, 119-128. [CrossRef] 